The effect of variations in the technique of the test upon the potency of different preparations of œstrin has been examined by J. H. Burn and G. K. Elphick $^{10}$, and by J. S. L. Browne ${ }^{11}$. Burn and Elphick found that the rat and mouse unit of trihydroxyoestrin were identical when the dose was injected in aqueous solution in five portions at intervals of 12 hours; Coward and Burn had previously obtained a similar result when the material was injected in a single dose in oily solution. It was found that when ketohydroxyœstrin was injected in aqueous solution in four doses into spayed rats it had 85 per cent of the activity of trihydroxycestrin, given under the same conditions, but that when it was injected in a single dose in oily solution it was 4.5 times more potent. Burn and Elphick quote figures showing that, according to the technique adopted, the potency of ketohydroxyœestrin varies from 940 to 3,000 rat units per mgm. or from 8,000 to 16,600 mouse units per mgm.; in the case of trihydroxyœstrin the variations are from 210 to 1,960 rat units per mgm. or from 1,510 to 8,000 mouse units per mgm. It is to be hoped that most of these variations will be eliminated by the general adoption of the international standard.

Browne has investigated the activity of the two œstrins with the use of adult and immature spayed rats, immature normal rats and immature spayed and grafted animals. The trihydroxyœestrin was isolated from human placenta and appears to be identical with Collip's emmenin : it is closely related to Doisy's theelol, which is, however, usually identified with trihydroxyœstrin. In all assays the total dose was given in aqueous solution in six injections over 36 hours, and the amount required to produce oestrus in 50 per cent of the animals determined. On the adult spayed rat, emmenin had a potency of about 68 units per mgm., whilst theelol was $5-10$ times more active and ketohydroxyœstrin (theelin) still more potent. On the immature intact animal emmenin had a potency of 550-1,100 units per mgm. The same result was obtained when the dose was given by mouth over three days, and theelol and theelin were equally active on subcutaneous injection. On the immature spayed rat, the potency of emmenin, injected 2-4 days after ovariectomy, was only 100-150 units per mgm. : theelol was three times more active. Transplantation of the ovaries from 21-day old rats into the spleen of immature ovariectomised animals reduced the dose of emmenin and theelol necessary to produce a positive response in 50 per cent of the animals injected to the amount required by the immature intact animal. It was found that ovariectomy did not change the sensitiveness of the animals to theelin, but that the first dose sensitises both normal and spayed animals to a subsequent injection of the same material, when the animals are injected every seven days.

The author suggests that the immature ovary increases the efficiency of utilisation of emmenin by increasing its rate of conversion into a more active œstrogenic substance, probably some form of ketohydroxyostrin. The low activity of emmenin in the adult spayed rat may be compared with the small figure given for the potency of trihydroxyœstrin by Butenandt, namely, 75 mouse units per mgm. It might be suggested that the employment of different types of test animals, in combination with the use of the international standard, would prove of value in the future in the identification and differentiation of this group of compounds.

2 Naturwiss., 21, $49 ; 1933$.

NATURE, 130, 238, Aug. 13, 1932

Chem. and Ind., 52,$289 ; 1933$.

26, 25 ; 1932 . F. Marrian and G. A. D. Haslewood: Biochem. $J$.

G. F. Marrian and G. A. D. Haslewood, Lancet, 2, 282; 1932 99, 327; 1933 . , 327 ; 1933.

${ }^{6}$ N. K. Adam, J. F. Danielli, G. A. D. Haslewood and G. F. Marrian Biochem. J., 26, 1233; 1932: Danielli, Haslewood and Marrian, ibid. 27,$311 ; 1933$

NATURE, 131, 56, Jan. 14, 1933.

${ }^{8}$ Chem. and Ind., 52,$288 ; 1933$.

Biochem. J., 26, 1227 ; 1932.

acol., 5, $192 ; 1932$

11 Canad. $J$. Res., 8, 180; 1933.

\title{
Cattle Research in Northern Queensland
}

$\mathrm{E}^{\mathrm{N}}$ NCOURAGING success has attended the first year's work at the Animal Health Research Station at Townsville in North Queensland, administered by the Commonwealth Council for Scientific and Industrial Research but financed by the Empire Marketing Board (50 per cent) and the graziers and Government of the State. Dr. A. W. Turner, officerin-charge, and Dr. Legg have restricted attention mainly to tick fever (redwater), pleuro-pneumonia and 'peg-leg' disease of cattle.

Formerly, tick fever in Australia was regarded as due solely to Piroplasma bigeminum, but following a visit to Onderstepoort, South Africa, Dr. Legg was able to identify three other organisms, Theileria mutans, Anaplasma marginale and a species of Babesiella. Of these, A. marginale causes quite a severe form of redwater and is probably a much more serious parasite than $P$. bigeminum. An explanation is therefore available of frequent past failures to immunise susceptible beasts by injecting blood taken from an animal which had recovered from the fever. The practice was satisfactory so far as $P$. bigeminum was concerned, but the unsuspected introduction of the virulent $A$. marginale often led to fatal results. As a vaccine against the latter, it may be necessary to use a weak strain of $A$. centrale from South Africa, since the adoption of the Queensland forms of $A$. marginale is scarcely possible because of their marked virulence.

Inoculation against pleuro-pneumonia with a virus obtained from a living animal in an advanced stage of the disease is often difficult in North Australia because of rapid deterioration and the immense distances over which the virus has to be transported: While endeavouring to develop better methods of immunisation, Dr. Turner has improved the existing position by showing that if the virus is dried under vacuum at a low temperature it can be kept satisfactorily for considerable periods.

Study of the blood complement fixation test has led to an improved method making possible with comparative ease the determination of carriers. This will be of practical importance over considerable areas, but particularly in. Western Australia where, though pleuro-pneumonia is infrequent, 'overlanding' cattle south from the 20 th parallel is forbidden lest carriers be present in the mob. This embargo is a serious matter for pastoralists.

'Peg-leg' disease is characterised by obvious malnutrition, stiffness of gait and frequent fractures of bones, and is a condition of great economic importance. A preliminary conclusion is that at least one 
of the causes of the trouble is phosphorus deficiency. Some of the soils near Charters Towers are lower in phosphorus than the worst South African soils reported upon by Sir Arnold Theiler and his co-workers. A special field station has been established by a number of pastoralists and decisive experiments are in progress.

Had it not been for the Empire Marketing Board, this work in Northern Queensland would not have been initiated. The abolition of the Board may perhaps be a logical sequel to the Ottawa Conference; but Empire team work in agricultural research will sadly miss its stimulus unless the Dominions, India and the Colonies rally to the support either of the Executive Council of the Imperial Agricultural Bureaux or of some new body fitted to take the vacant place in this respect.
A. C. D. R.

\section{Panstereoscopic Photography}

$\mathrm{T}$ HE thirty-first Traill-Taylor Memorial Lecture was delivered before the Royal Photographic Society on Tuesday, October 3. The lecturer was Dr. H. E. Ives, of the Bell Telephone Laboratories, who chose as his subject "Panstereoscopic Photography and Cinematography".

Ordinary stereoscopic pictures consist of two views, taken from two positions. When observed by some device (a stereoscope) which presents one view to each eye, a single image is seen, exhibiting solidity or relief. A limitation of this simple stereoscopic system is that each observer of such a pair of pictures must be equipped with apparatus closely in front of his eyes. If stereoscopic pictures are projected upon a screen, this requirement demands as large a number of viewing devices as there are spectators.

Viewing apparatus at the eyes may be eliminated if the direction of the two views to their appropriate eyes can be done from the plane of the pictures. The first device to do this was the parallax stereogram of Frederic E. Ives. The two stereoscopic pictures were divided into many narrow alternating strips, and placed behind and slightly separated from a grid or grating, the clear spaces of which exposed all the elements comprising one image to one eye, and those comprising the other image to the other eye. Photographic transparencies made in this way show stereoscopic relief, but must be observed from a definite direction and distance.

A further extension of this idea was made by C. W. Kanolt, who substituted for the pairs of image strips, a series, forming minute panoramas. These, when viewed through a grating with very narrow clear spaces, or through a transparent plate impressed with cylindrical lenticular ridges, show stereoscopic relief through a wide observing angle, the range of distances.

Parallax panoramagrams, as these pictures have been called, can be adapted for projection to large size, by using a projection screen consisting of cylindrical lens elements, on the back of which the panoramic strip images are imaged in accurate registration. The step from this to the projection of moving pictures exhibiting stereoscopic relief depends upon the possibility of taking the original panoramic strip negatives by instantaneous exposures, and upon means for the accurate registration, at high speeds, of the projected images. The earlier parallax panoramagrams were made by moving cameras, necessitat. ing exposure times quite prohibitive for motion pictures.

Recently a form of camera has been developed which embodies a large diameter concave mirror, the various elements of which view the object from a wide range of angles, which in combination with a grating over the sensitive plates, makes possible instantaneous exposures. The projection of these, constituting an experimental demonstration of motion pictures in relief, has been accomplished by mounting a series upon a continuously rotating metal disc, illuminated by a flashing lamp. The extreme accuracy of registration required in projection and the overall complexity of the process make its practical application to film appear remote. This development does, however, constitute a sound scientific solution of the problem.

\section{Organisation as a}

A

DISCUSSION arranged by the Department of Industrial Co-operation of Section F (Economic Science and Statistics) at the British Association meeting at Leicester on September 7 was devoted to "Organisation as a Technical Problem". Dr. E. F. Armstrong, who presided, emphasised the place which scientific management should hold in the conduct of modern industrial enterprise and referred to the Sixth International Congress for Scientific Management to be held in London in July 1935 under the presidency of Sir George Beharrell. The programme of this Congress includes the consideration of the principles of scientific management in smallor medium-sized works, budgetary control of production and forecasting as well as training with particular reference to the supply of men for the larger commercial undertakings and public administration. Many of the normal actions and methods of business are unscientific and, even if of monetary use to the individual, are injurious to a trade as a whole, to the State and to the community. There is a great opportunity and need for definite constructive

\section{Technical Problem}

work, and in particular, Dr. Armstrong stressed the opportunity for the application of scientific method to salesmanship.

Major L. Urwick urged that there are principles which can be reached inductively from the study of human experience of organisation and should govern arrangements for human associations of any kind. Such principles can be studied as a technical question irrespective of the purpose of the enterprise, its personnel and any constitutional, political or social theory underlying its creation. They cover the method of subdividing and allocating to individuals all the various activities, duties and responsibilities essential to the purpose contemplated, the correlation of those activities and the continuous control of the work of individuals so as to secure the most economic and efficient realisation of the purpose. It is almost impossible to exaggerate the practical importance of this subject in existing world conditions, which are largely caused by humanity's failures in its capacity for association or organisation.

A critical review of recent literature on organisation 